\title{
Advanced Byproduct Recovery: \\ Direct Catalytic Reduction of Sulfur Dioxide to Elemental Sulfur
}

Seventh Quarterly

Technical Progress Report

Report to Department of Energy Pittsburgh Energy Technology Center Under Contract \# DE-AC-95PC95252

June, 1997

Arthur D. Little, Inc. Acorn Park

Cambridge, Massachusetts 02140-2390

Tufts University

Medford, Massachusetts 02155

Engelhard Corporation

Edison, NJ 08818

Reference 54177 


\section{TABLE OF CONTENTS}

INTRODUCTION

$\begin{array}{ll}\text { Background } & 5\end{array}$

Description of Byproduct Recovery System 5

$\begin{array}{ll}\text { Research and Development Activity } & 6\end{array}$

WORK BREAKDOWN STRUCTURE $\quad 8$

$\begin{array}{lr}\text { Phase I Task 1: Market, Process and Cost Evaluation } & 8\end{array}$

Phase I Task 2: Lab-Scale Catalyst Testing/Optimization 9

$\begin{array}{ll}\text { Phase I Task 3: Catalyst Preparation and Costing } & 10\end{array}$

Phase I Task 4: Bench-scale Testing $\quad 11$

Phase I Task 5: Utility Review $\quad 12$

Phase I Task 6: Management and Reports 12

OBJECTIVES FOR SEVENTH QUARTER ACTIVITY 12

SEVENTH QUARTER TECHNICAL PROGRESS 13

$\begin{array}{ll}\text { Background } & 13\end{array}$

$\begin{array}{ll}\text { Tufts } & 14\end{array}$

$\begin{array}{ll}\text { Arthur D. Little } & 22\end{array}$

$\begin{array}{ll}\text { Engelhard } & 23\end{array}$

REFERENCES: $\quad 23$ 


\section{LIST OF FIGURES}

Figure 1-1: Regenerable Sorbent System 5

Figure 1-2: Work Elements

Figure 4-1. Reduction of $1.05 \% \mathrm{SO}_{2}$ by $\mathrm{CO}$ over ceria and promoted ceria with and without adding $10 \%$ water (at either $450^{\circ} \mathrm{C}$ or $500^{\circ} \mathrm{C}$ as indicated by the arrows). Contact time $=$ $0.11 \mathrm{~g} \mathrm{~s} / \mathrm{cm}^{3}, \mathrm{CO} / \mathrm{SO}_{2}=1.5$ to 1.6. Catalysts: $-\mathrm{Ce}(10 \% \mathrm{Zr}) \mathrm{O}_{2} ; \mathbf{\square},-\mathrm{Ce}(10 \% \mathrm{La}) \mathrm{O}_{2}$;

$\boldsymbol{\Delta},-\mathrm{CeO}_{2}$. Filled symbols represent conversion of $\mathrm{SO}_{2}$; open symbols represent yield to $\mathrm{H}_{2} \mathrm{~S}$..

Figure 4-2. Reduction of $1.1 \% \mathrm{SO}_{2}$ by $\mathrm{CO}$ over $\mathrm{Ce}(10 \% \mathrm{Zr}) \mathrm{O}_{2}$ at $500^{\circ} \mathrm{C}$. Conditions: contact time $=0.11 \mathrm{~g} \mathrm{~s} / \mathrm{cm}^{3}, \mathrm{CO} / \mathrm{SO}_{2}=1.51$. At the indicated times, $10 \%$ water was added or removed from the inlet stream. Filled symbols represent conversion of $\mathrm{SO}_{2}$; open symbols represent yield to $\mathrm{H}_{2} \mathrm{~S}$.

Figure 4-3. Reduction of $1.05 \% \mathrm{SO}_{2}$ by $\mathrm{CO}$ in the presence of $10 \%$ water. Conditions: contact time $=0.11 \mathrm{~g} \mathrm{~s} / \mathrm{cm}^{3}$ (except as indicated), $\mathrm{CO} / \mathrm{SO}_{2}=1.5-1.7$. Catalysts: $\bigcirc$ $\mathrm{Ce}(10 \% \mathrm{Zr}) \mathrm{O}_{2} ; \mathbf{\square},-\mathrm{Ce}(10 \% \mathrm{La}) \mathrm{O}_{2} ; \boldsymbol{\Delta}, \triangle-\mathrm{CeO}_{2} ; \mathrm{t},-10 \% \mathrm{Ni}\left[\mathrm{Ce}(5 \% \mathrm{La}) \mathrm{O}_{\mathrm{x}}\right] ; \mathrm{u},-$ $10 \% \mathrm{Ni}\left[\mathrm{Ce}(5 \% \mathrm{La}) \mathrm{O}_{\mathrm{x}}\right]$ pre-reduced at $600^{\circ} \mathrm{C}$ in flowing hydrogen; $\mathrm{z},-\mathrm{Ni}_{\mathrm{y}}\left[\mathrm{Ce}\left(\mathrm{La}_{1-\mathrm{y}}\right) \mathrm{O}_{\mathrm{x}}\right]$. Filled symbols represent conversion of $\mathrm{SO}_{2}$; open symbols represent yield to $\mathrm{H}_{2} \mathrm{~S}$.

Figure 4-4. Effect of catalysts composition on $\mathrm{SO} 2$ reduction by $\mathrm{CH} 4$. Catalysts: $\bullet-5 \% \mathrm{Ni}-$

$\mathrm{Ce}(\mathrm{La})-\mathrm{O} ; \mathbf{\square}, \quad: 5 \% \mathrm{Cu}-\mathrm{Ce}(\mathrm{La})-\mathrm{O} ; \mathrm{s}, \mathrm{s}: 4.5 \% \mathrm{La}-\mathrm{Ce}-\mathrm{O}$. Conditions: $1 \% \mathrm{SO}_{2}-1 \% \mathrm{CH}_{4}-$ balance $\mathrm{He}$, contact time $0.18 \mathrm{gs} / \mathrm{cm}^{3}$.

Figure 4-5. Effect of contact time on $\mathrm{SO}_{2}$ reduction by $\mathrm{CH}_{4}$. Catalyst: $5 \% \mathrm{Cu}-\mathrm{Ce}(\mathrm{La})-\mathrm{O}$.

Conditions: $1 \% \mathrm{SO}_{2}-1 \% \mathrm{CH}_{4}$-balance $\mathrm{He}$, contact time $\mathbf{0}, 0.18 \mathrm{gs} / \mathrm{cc}, \mathbf{\square},: 0.72 \mathrm{gs} / \mathrm{cc}$ and $\boldsymbol{\Delta}, \triangle: 1.2 \mathrm{gs} / \mathrm{cm}^{3}$.

Figure 4-6. Effect of $\mathrm{CH}_{4} / \mathrm{SO}_{2}$ ratio on $\mathrm{SO}_{2}$ reduction by $\mathrm{CH} 4$. Catalyst: $5 \% \mathrm{Cu}-\mathrm{Ce}(\mathrm{La})-\mathrm{O}$.

Conditions: $1 \% \mathrm{SO}_{2}$, contact time $0.18 \mathrm{gs} / \mathrm{cm}^{3}, \mathrm{CH}_{4} / \mathrm{SO}_{2}:-,-1 ; \mathbf{\square},-2 ; \mathbf{\Lambda}, \triangle-3$. . 19

Figure 4-7. Effect of water on $\mathrm{SO}_{2}$ reduction by $\mathrm{CH}_{4}$. Conditions: $1 \% \mathrm{SO}_{2}-2 \% \mathrm{CH}_{4}-\mathrm{He}$, contact time $0.18 \mathrm{gs} / \mathrm{cm}^{3}$.

Figure 4-8. Effect of metal on the reduction of $\mathrm{SO}_{2}$ by $\mathrm{H}_{2}$ : activity of $\mathrm{Ce}(\mathrm{La}) \mathrm{O}_{x}$. Catalysts: $4.5 \% \mathrm{La}-\mathrm{Ce}-\mathrm{O} ; \mathbf{\square}, \quad: 5 \% \mathrm{Fe}-\mathrm{Ce}(\mathrm{La})-\mathrm{O} ; \boldsymbol{\Delta}, \triangle: 5 \% \mathrm{Cu}-\mathrm{Ce}(\mathrm{La})-\mathrm{O} ; \diamond, \quad: 5 \% \mathrm{Ni}-\mathrm{Ce}(\mathrm{La})-$ O.Conditions: $1 \% \mathrm{SO}_{2}-2 \% \mathrm{H}_{2}-\mathrm{He}$, contact time $0.18 \mathrm{gs} / \mathrm{cm}^{3}$.

Figure 4-9. Effect of metal content on the reduction of $\mathrm{SO}_{2}$ by $\mathrm{H}_{2}$. Catalysts: $-15 \% \mathrm{Fe}-$ $\mathrm{Ce}(\mathrm{La})-\mathrm{O} ; \mathbf{\square}, \quad: 5 \% \mathrm{Fe}-\mathrm{Ce}(\mathrm{La})-\mathrm{O}$. Conditions: $1 \% \mathrm{SO}_{2}, 2 \% \mathrm{H}_{2}$, balance He, contact time $0.18 \mathrm{gs} / \mathrm{cm}^{3}$. 


\section{LIST OF TABLES}

TABLE 4-1. PHYSICAL PROPERTIES AND ACTIVITY OF CERIA AND DOPED CERIA 


\section{Introduction}

\section{Background}

More than 170 wet scrubber systems applied, to 72,000 MW of U.S., coal-fired, utility boilers are in operation or under construction. ${ }^{1}$ In these systems, the sulfur dioxide removed from the boiler flue gas is permanently bound to a sorbent material, such as lime or limestone. The sulfated sorbent must be disposed of as a waste product or, in some cases, sold as a byproduct (e.g. gypsum). Due to the abundance and low cost of naturally occurring gypsum, and the costs associated with producing an industrial quality product, less than $7 \%$ of these scrubbers are configured to produce useable gypsum ${ }^{2}$ (and only $1 \%$ of all units actually sell the byproduct). The disposal of solid waste from each of these scrubbers requires a landfill area of approximately 200 to 400 acres. In the U.S., a total of 19 million tons of disposable FGD byproduct are produced, transported and disposed of in landfills annually. ${ }^{3}$

The use of regenerable sorbent technologies has the potential to reduce or eliminate solid waste production, transportation and disposal. In a regenerable sorbent system, the sulfur dioxide in the boiler flue gas is removed by the sorbent in an adsorber. The $\mathrm{SO}_{2}$ is subsequently released, in higher concentration, in a regenerator. All regenerable systems produce an off-gas stream from the regenerator that must be processed further in order to obtain a saleable byproduct, such as elemental sulfur, sulfuric acid or liquid $\mathrm{SO}_{2}$. A schematic of a regenerable sorbent system is shown below.

Figure 1-1: Regenerable Sorbent System

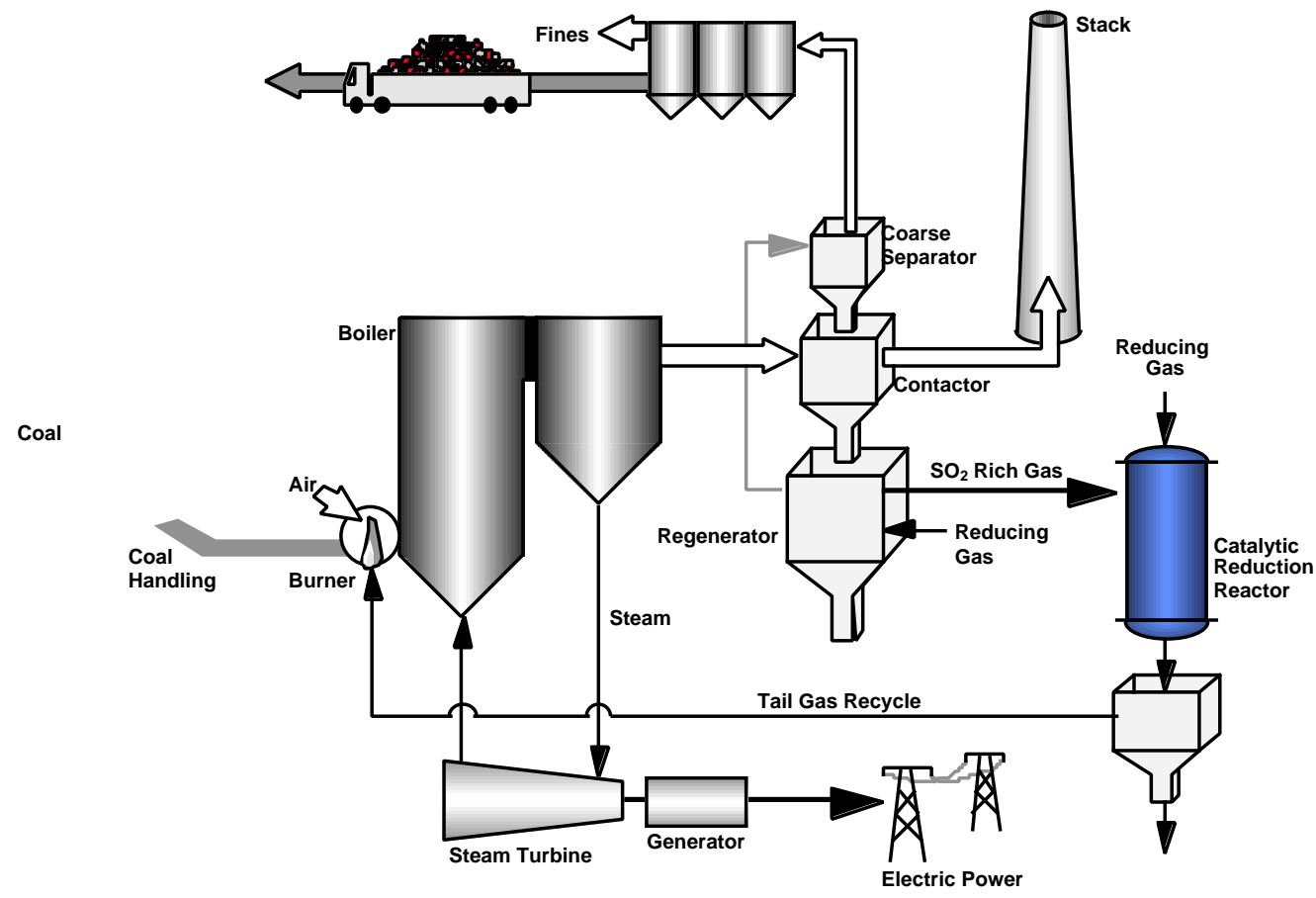

In addition to reducing solid waste, many regenerable systems have other benefits compared to non-regenerable scrubbing technologies, including higher sulfur removal efficiencies, and the capability of combined $\mathrm{SO}_{2} / \mathrm{NO}_{x}$ removal.

\section{Description of Byproduct Recovery System}

The team of Arthur D. Little, Tufts University and Engelhard Corporation are conducting Phase I of a four and a half year, two-phase effort to develop and scale-up an advanced byproduct 
recovery technology that is a direct, single-stage, catalytic process for converting sulfur dioxide to elemental sulfur. This catalytic process reduces $\mathrm{SO}_{2}$ over a fluorite-type oxide (such as ceria and zirconia). The catalytic activity can be significantly promoted by active transition metals, such as copper. More than $95 \%$ elemental sulfur yield, corresponding to almost complete sulfur dioxide conversion, was obtained over a $\mathrm{Cu}-\mathrm{Ce}-\mathrm{O}$ oxide catalyst as part of an on-going DOEsponsored, University Coal Research Program (at MIT with Dr. Flytzani-Stephanopoulos). This type of mixed metal oxide catalyst has stable activity, high selectivity for sulfur production, and is resistant to water and carbon dioxide poisoning. Tests with $\mathrm{CO}$ and $\mathrm{CH}_{4}$ reducing gases indicate that the catalyst has the potential for flexibility with regard to the composition of the reducing gas, making it attractive for utility use. The performance of the catalyst is consistently good over a range of $\mathrm{SO}_{2}$ inlet concentration (0.1 to 10\%) indicating its flexibility in treating $\mathrm{SO}_{2}$ tail gases as well as high concentration streams.

\section{Research and Development Activity}

Arthur D. Little, Inc., together with its industry and commercialization advisor, Engelhard Corporation, and its university partner, Tufts, plans to develop and scale-up an advanced, byproduct recovery technology that is a direct, catalytic process for reducing sulfur dioxide to elemental sulfur. The principal objective of our Phase I program is to identify and evaluate the performance of a catalyst which is robust and flexible with regard to choice of reducing gas.

In order to achieve this goal, we have planned a structured program including:

Market/process/cost/evaluation;

Lab-scale catalyst preparation/optimization studies;

Lab-scale, bulk/supported catalyst kinetic studies;

Bench-scale catalyst/process studies; and

Utility Review

The flow of and interaction among the planned work elements are illustrated in for Phase I. A description of the methods of investigation to be used for these program elements is described below.

Market, Process and Cost Evaluation. Interviews will be conducted with electric utilities and regenerable sorbent system developers to define key market issues, such as: preferred reducing gas; variability of off-gas stream composition; system contaminants; emissions limitations; cost constraints; and reliability/durability issues. From the interview responses, key performance criteria for the system will be defined. The performance and cost of the proposed catalytic process will be evaluated and compared to these criteria. In addition, these performance criteria will be used to define milestones and to focus catalyst and process development. 
Figure 1-2: Work Elements

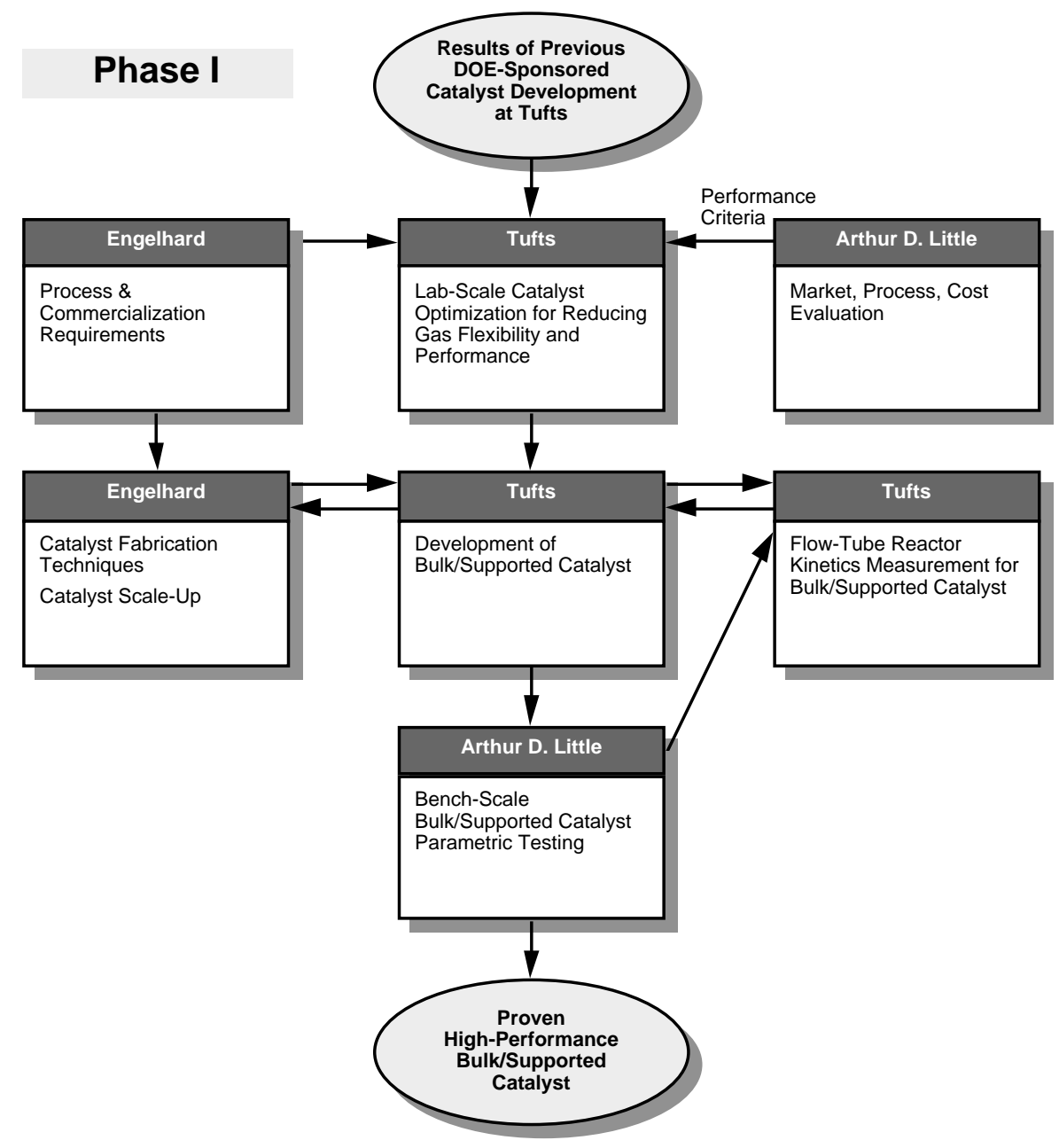

Lab-scale Catalyst Preparation/Optimization Studies. Catalyst will be prepared using a variety of methods (such as co-precipitation, sol-gel technique) from two candidate fluorite oxides $\left(\mathrm{CeO}_{2}, \mathrm{ZrO}_{2}\right)$ and four candidate transition metals $(\mathrm{Cu}, \mathrm{Co}, \mathrm{Ni}, \mathrm{Mo})$. These catalyst materials will be tested at Tufts in the same apparatus as was used in the previous work discussed above with a variety of reducing gases $\left(\mathrm{CO}, \mathrm{CO}+\mathrm{H}_{2}, \mathrm{CH}_{4}\right)$. Data will be gained in order to determine the key underlying reaction mechanisms. Parametric tests will determine the relative effects of temperature, concentration, space velocity, catalyst preparation method, and reducing gas. To reduce the amount of screening work, statistical experiment design methods will be used and catalyst characterization will be used to discriminate between active compositions. Some catalyst characterization work (x-ray diffraction, microscopy) will be conducted by Tufts staff at MIT laboratories.

Lab-scale, Bulk/Supported Catalyst Kinetic Studies. The best-performing catalysts will then be either appropriately supported (pellet, tablets, honeycomb, etc.) or formulated in bulk form. The bulk/supported catalyst will be tested in a laboratory-scale flow-tube reactor at Tufts to determine kinetic data.

Bench-scale Catalyst/Process Studies. Larger quantities of the bulk/supported catalyst will be tested in a bench-scale flow tube reactor at Arthur D. Little. Parametric tests will be conducted to 
assess the influence of temperature, inlet $\mathrm{SO}_{2}$ concentration, space velocity, and choice of reducing gas on performance. Some cyclic and duration testing will also be conducted at this scale.

Utility Review. A utility review team will be assembled, consisting of one or more utilities that have experience with regenerable desulfurization technologies or are considering their application in the near future. We will work closely with the utilities to inform them of the developments and solicit their perspective on utility needs and development issues.

\section{Work Breakdown Structure}

\section{Phase I Task 1: Market, Process and Cost Evaluation}

\section{Lead Contractor: Arthur D. Little}

\section{Objectives:}

To identify the critical market forces, technical requirements and cost constraints in order to focus the catalyst/byproduct recovery process research effort;

To evaluate the costs and benefits of the advanced byproduct recovery process, and to compare these attributes to those of state-of-the-art technologies;

To determine the extent to which application of the advanced byproduct recovery process improves the competitiveness of regenerable sorbent systems.

\section{Approach:}

This task is being conducted by Arthur D. Little. We are interviewing utilities, leading architect/engineering companies, regenerable sorbent system developers, industry consultants and EPRI to define key market issues, including: preferred reducing gas; variability of $\mathrm{SO}_{2}$-rich off-gas stream composition; compatibility/flexibility in coupling with the adsorption/regeneration step; system contaminants; emissions limitations; cost constraints; and reliability/durability issues. Based on these interviews, we will define the key performance criteria for the system. We will estimate the potential market for advanced, catalytic reduction of $\mathrm{SO}_{2}$ to elemental sulfur in utility and industrial applications.

We are preparing a Process Evaluation, in which we will prepare or specify process energy balances, temperature requirements, reactor volumes, and recycle rates, for one or more reducing gas production methods. These analyses will be tied to the requirements of utilities and the various regenerable sorbent technologies under development. We are also preparing a Cost Evaluation of the byproduct recovery system in the context of its use with one or more regenerable $\mathrm{SO}_{2}$ removal systems and compare the costs of the proposed technology to that of state-of-the-art technology.

\section{Deliverables:}

Market, process and cost analyses of the proposed byproduct recovery system; definition of key areas to focus research efforts; assessment of the potential market for the process. 


\section{Phase I Task 2: Lab-Scale Catalyst Testing/Optimization}

\section{Lead Contractor: Tufts}

\section{Objectives:}

To optimize catalyst composition and preparation method for use with a variety of reducing gas compositions and qualities, including syn-gas and natural gas.

\section{Approach:}

This task is being carried out by Tufts University, a subcontractor to Arthur D. Little. Under four subtasks, Tufts will prepare and characterize the catalysts, conduct adsorption/desorption studies, measure catalytic activity in a packed-bed microreactor, and conduct parametric tests and kinetic measurements. Specifically, Tufts will optimize the catalyst composition and preparation method for use with a variety of reducing gas compositions and qualities, including synthesis gas and natural gas.

The transition metal-promoted fluorite-type oxides previously identified as very active and selective catalysts for the reduction of $\mathrm{SO}_{2}$ to elemental sulfur with carbon monoxide will be tested with other reductants, namely synthesis gas $\left(\mathrm{H}_{2}\right.$ and $\mathrm{CO}$ mixed with $\mathrm{H}_{2} \mathrm{O}$ and $\left.\mathrm{CO}_{2}\right)$ and natural gas. Various transition metals (including $\mathrm{Cu}, \mathrm{Co}, \mathrm{Ni}$, and $\mathrm{Mo}$ ) will be examined as promoters to obtain a catalyst composition active in various reducing gases. The fluorite oxides to be used in this work are ceria $\left(\mathrm{CeO}_{2}\right)$ and zirconia $\left(\mathrm{ZrO}_{2}\right)$.

Arthur D. Little, with assistance from Tufts, will develop a detailed Test Plan for the laboratoryscale catalyst testing and optimization activities. The Test Plan will be submitted as an amendment to the Management Plan. No testing will begin until the Test Plan has been approved by the DOE Project Manager.

Catalyst Preparation and Characterization Tufts will prepare the catalysts by the coprecipitation method to produce a surface area in the range of $20-60 \mathrm{~m}^{2} / \mathrm{g}$. To achieve high surface area, high elemental dispersion, and uniform pore-size distribution, other preparation techniques (such as gelation and impregnation of high surface area supports) will also be examined.

Catalysts will routinely be characterized by X-ray powder diffraction for crystal phase identification and by nitrogen adsorption/desorption for BET surface area and pore size distribution measurements. The elemental composition of the catalyst will be analyzed Inductively Coupled Plasma Atomic Emission Spectrometry. Selected active catalysts will be further characterized by X-ray Photoelectron Spectroscopy (XPS) and Scanning Transmission Electron Microscopy (STEM).

Adsorption/Desorption Studies In parallel with the preparation of the new catalyst composition, the $\mathrm{Cu}-\mathrm{Ce}-\mathrm{O}$ catalyst will be evaluated in adsorption/desorption studies with $\mathrm{CO}, \mathrm{COS}$, and $\mathrm{SO}_{2}$ to determine the reaction mechanism. These experiments will lead to an understanding of the low selectivity of this catalyst to the undesirable byproduct COS and facilitate catalyst optimization. A thermo-gravimetric analyzer, coupled with a residual gas analyzer, will be used for these tests.

Catalytic Activity Measurements in a Packed-Bed Microreactor Tufts will conduct catalyst activity tests under steady conditions in an existing packed- bed microreactor. Screening tests will be conducted with a reducing gas consisting of $1 \% \mathrm{SO}_{2}$ and $0.5 \% \mathrm{CH}_{4}$. Additional tests of 
the most promising catalysts will be conducted with two additional synthesis reducing gases. However, final selection of reducing gases will be made based on input from regenerable sorbent system developers and utilities (the Task 1 findings). We currently envision the two additional synthesis test gases to be:

(i) wet feed gas mixture containing $1 \% \mathrm{SO}_{2}$ and stoichiometric amount of synthesis gas with $\mathrm{H}_{2} / \mathrm{CO}=0.3,2 \% \mathrm{H}_{2} \mathrm{O}$ and $2 \% \mathrm{CO}_{2}$; and

(ii) wet feed gas mixture containing $1 \% \mathrm{SO}_{2}$, stoichiometric amount of synthesis gas with $\mathrm{H}_{2} / \mathrm{CO}=3,2 \% \mathrm{H}_{2} \mathrm{O}$, and $2 \% \mathrm{CO}_{2}$.

The existing data on performance with pure $\mathrm{CO}$ and the new data to be developed using methane and wet synthesis gases will cover the range of possible regeneration gases available. It is not necessary to test dry synthesis gases since the tests with $\mathrm{CO}$ and methane provides information on ideal performance without water. For each reacting gas mixture, the reactor temperature will be increased and then reduced to establish light-off and fall-off behavior of each catalyst. Elemental sulfur yield, catalyst activity and catalyst selectivity will be used to identify the most promising catalysts.

Parametric Studies and Kinetic Measurements After identifying promising catalysts, an extensive parametric study and kinetic measurements will be carried out to provide reactor design information. The parametric studies will address:

(i) the effects of water vapor and/or carbon dioxide on catalyst activity and elemental sulfur yield; and

(ii) effect of reducing gas composition $\left(\mathrm{H}_{2} / \mathrm{CO}\right.$ ratios/ $\left.\mathrm{CH}_{4}\right)$ on catalyst activity and sulfur yield.

Long-term and hydrothermal catalyst stability will be evaluated for the preferred catalyst composition in Task 4, Bench-Scale Testing.

The parametric studies will be conducted at space velocities in the range 1,000 to $100,000 \mathrm{~h}^{-1}$, $\mathrm{SO}_{2}$ concentrations from $0.1 \%$ to $10 \%, \mathrm{H}_{2} \mathrm{O}$ contents from 0 to $10 \%, \mathrm{H}_{2} / \mathrm{CO}$ ratios from 0 to 3 , and $\mathrm{CH}_{4}$ concentrations from $0.1 \%$ to $10 \%$. The temperature will be in the range 50 to $700^{\circ} \mathrm{C}$. A kinetic model will be developed from the data obtained at short contact time $(<0.1 \mathrm{~g} \mathrm{~s} / \mathrm{cc})$ in a small diameter catalytic reactor. This will include the effects of $\mathrm{H}_{2} \mathrm{O}$ and $\mathrm{CO}_{2}$ on the specific activity.

\section{Deliverables:}

An optimized catalyst composition/preparation method for bench-scale catalyst tests. Kinetic data for use in reactor design.

\section{Phase I Task 3: Catalyst Preparation and Costing Lead Contractor: Engelhard}

\section{Objectives:}

Provide guidance regarding the establishment of activity and simulated aging tests to quickly and efficiently determine performance characteristics of catalyst formulations;

To prepare supported or bulk (extruded) catalysts in the form of pellets or honeycombs for bench-scale testing; 
To provide catalyst manufacturing and cost analysis for inclusion in the analysis of process economics.

\section{Approach:}

Engelhard will work closely with Tufts and Arthur D. Little to specify the appropriate catalyst structures to meet the engineering requirements for the targeted sulfur recovery systems. Included in this activity will be the training of scientists and engineers on the Tufts team by Engelhard staff members in the formulation of commercially viable catalyst structures. Engelhard staff will observe and participate in laboratory-scale and bench-scale testing at Tufts and Arthur D. Little to interpret/analyze results. The resulting analysis will be used to redesign catalysts which resist deactivation.

Engelhard will apply their expertise in process and cost evaluation of catalytic systems to the sulfur byproduct recovery system. Engelhard will provide catalyst manufacturing cost details to allow the process economics to be established.

\section{Deliverables:}

Catalysts for bench-scale testing; manufacturing/cost analysis of catalysts for inclusion in system evaluation task.

\section{Phase I Task 4: Bench-scale Testing}

\section{Lead Contractor: Arthur D. Little}

\section{Objectives:}

To conduct bench-scale, parametric tests to evaluate the performance of three to five supported/extruded catalyst preparations.

\section{Approach:}

Arthur D. Little will develop a Test Plan for the bench-scale parametric tests and will incorporate this plan into an amendment to the Management Plan. No work will begin on the bench-scale tests until the Test Plan has been approved by the DOE Project Manager. Arthur D. Little is designing, and will fabricate and commission a bench-scale $\mathrm{SO}_{2}$ reduction reactor facility. The facility will consist of gas supply controls (for the simulated regenerator off-gas stream and the reducer gas stream); gas heaters; a catalytic reduction reactor (approximately 1-2 1 in size); a heat exchanger for sulfur knock-out; gas analysis instrumentation $\left(\mathrm{SO}_{2}, \mathrm{H}_{2} \mathrm{~S}\right.$ on-line analyzers, gas chromatograph) and an afterburner for clean-up of off-gases. The system will be fabricated and shaken-down in the first 6 months of the program following approval of the Management Plan.

We will initiate bench-scale tests using the catalyst materials that have been proven as highly active and selective for sulfur production from the previous/ongoing catalyst development programs: a copper promoted ceria catalyst, $\mathrm{Ce}-\mathrm{Cu}-\mathrm{O}$. Tests on supported materials will reveal the performance changes associated with the use of supported or bulk extruded materials compared to powders. We will investigate the effects of space velocity, temperature, and reducer gas and regenerator gas composition on catalyst performance. 
Subsequent parametric tests will be performed on catalyst formulations selected from the labscale catalyst optimization work. The operating variables are expected to be as follows: space velocity: $10,000,25,000,50,000 \mathrm{hr}^{-1}$; temperature: $450,500,600^{\circ} \mathrm{C}$; inlet stream composition: $\mathrm{SO}_{2}$ concentration: 0.1 to $10 \% ; \mathrm{H}_{2} \mathrm{O}$ concentration 2 to $30 \% ; \mathrm{CO}_{2}$ concentration 2 to $30 \%$; reducing gas composition: $\mathrm{CO} / \mathrm{H}_{2}$ ratio: 0.5 to $3.0 ; \mathrm{CO} / \mathrm{CO}_{2}$ ratio: 0.5 to 3.0. Information developed from this task will provide insights for the process evaluation task, the catalyst optimization work, and the Phase II efforts in reactor scale-up.

\section{Deliverables:}

Performance map for 3 to 5 catalyst preparations; selection of catalyst preparation for dynamic response and pilot-scale testing.

\section{Phase I Task 5: Utility Review \\ Lead Contractor: Arthur D. Little}

\section{Objectives:}

To provide electric utility perspective and review of development program

To focus development effort on issues of key importance to utilities

\section{Approach:}

We will identify a utility review team, consisting of one or more utilities that have experience with regenerable desulfurization technologies or are considering their application in the near future. We will work closely with the utilities to inform them of the developments and solicit their perspective on utility needs and development issues. We plan to communicate through monthly meetings and will share data as it becomes available. Possible Utility Review Team members are Niagara Mohawk, Public Service of New Mexico, and Ohio Edison. All these utilities are participants in either regenerable sorbent programs or Clean Coal Development programs and would therefore have a valuable perspective to provide to our program, and would have a stake in the development of an improved byproduct recovery system.

\section{Deliverables:}

Utility review of the bench-scale developments; input to developments concerning issues of key importance to utilities.

\section{Phase I Task 6: Management and Reports}

\section{Lead Contractor: Arthur D. Little}

This task will be conducted by Arthur D. Little and will involve coordinating the catalyst/process development effort, coordinating the activities of the prime contractor and two subcontractors, and preparing the monthly, quarterly, topical, and final reports for DOE.

\section{Objectives for Seventh Quarter Activity}

The objectives for the seventh quarter were to: 
Continue work on catalyst screening using the laboratory-scale packed bed reactor. Effects of dopant type, dopant level, reducing gas type, stoichiometry, and temperature on selectivity and activity of a range of fluorite-type catalysts will be assessed.

Continue to examine catalysts containing $\mathrm{Cu}, \mathrm{Co}, \mathrm{Ni}$ and Mo. High surface area $\left(150 \mathrm{~m}^{2} / \mathrm{g}\right)$ ceria samples recently obtained from Engelhard will be impregnated with nitrate salts of the metals under consideration. The performance of the supported catalysts will be compared to that of the bulk mixed oxide catalysts.

To examine the effect of water vapor on the best catalyst of each type. Other reducing gases, such as synthesis gas, will be tested.

To characterize catalysts by X-ray powder diffraction for crystal identification and by nitrogen adsoption/desorption for BET surface area and pore size distribution measurements. The elemental composition of the catalyst will be analyzed using Inductively Coupled Plasma Atomic Emission Spectrometry.

To complete fabrication of the bench-scale experiment, conduct shake-down tests and to refine the plan for the larger scale experiments.

To assemble a team of industry experts to assist in evaluating the results of our research in the context of practical experience.

This report summarizes the results of the catalyst screening experiments at Tufts and the progress on the larger scale reactor.

\section{Seventh Quarter Technical Progress}

\section{Background}

In previous DOE-supported work, ${ }^{4}$ the activity and selectivity of fluorite-type oxides, such as ceria and zirconia, for reduction of $\mathrm{SO}_{2}$ were investigated. A wide range of transition metalimpregnated ceria and zirconia catalyst formulations were evaluated in a packed bed reactor, under both dry gas and wet gas $\left(2 \% \mathrm{H}_{2} \mathrm{O}\right)$ conditions. Under dry gas conditions, more than $95 \%$ yield of elemental sulfur and essentially complete $\mathrm{SO}_{2}$ conversion were obtained for a variety of catalysts. Under wet gas conditions, $\mathrm{Cu} / \mathrm{CeO}_{2}$ catalyst showed the lowest light-off temperature, the greatest resistance to water, and gave over $90 \% \mathrm{SO}_{2}$ conversion and more than $70 \%$ elemental sulfur yield.

Based on these results, and the fact that a 25 hour test indicated that the $\mathrm{Cu} / \mathrm{CeO}_{2}$ catalyst was stable at the reacting conditions, the $\mathrm{Cu}-\mathrm{Ce}-\mathrm{O}$ system was selected for detailed studies of the $\mathrm{SO}_{2}$ reaction with $\mathrm{CO}$. The effects of copper content, temperature, presence of water, and presence of $\mathrm{CO}_{2}$ on the selectivity and activity of this catalyst system were evaluated. This work led to the selection of bulk $\mathrm{Cu}_{0.15} \mathrm{Ce}_{0.85}(\mathrm{La}) \mathrm{O}_{\mathrm{x}}$ for further study. More than $95 \%$ elemental sulfur yield, corresponding to almost complete sulfur dioxide conversion, was obtained over a $\mathrm{Cu}-\mathrm{Ce}-\mathrm{O}$ oxide catalyst with a feed gas of stoichiometric composition $\left([\mathrm{CO}] /\left[\mathrm{SO}_{2}\right]=2\right)$ at temperatures above $450^{\circ} \mathrm{C}$. This catalyst showed no apparent deactivation during a 35-hour run in the presence of $2 \%$ water at $470^{\circ} \mathrm{C}$. In addition, the performance of this catalyst with other reducing gases was briefly investigated. Elemental sulfur yields of $50-66 \%$ were obtained using $\mathrm{H}_{2}$ at $600^{\circ} \mathrm{C}$ and an elemental sulfur yield of $72 \%$ was obtained using $\mathrm{CH}_{4}$ at $800^{\circ} \mathrm{C}$. It is noteworthy that all tests mentioned above were conducted at high space velocities, on the order of $40-50,000 \mathrm{~h}^{-1}(\mathrm{STP})$. 
Thus previous work has shown that the catalytic activity of fluorite-type oxides, such as ceria and zirconia, for the reduction of sulfur dioxide by carbon monoxide to elemental sulfur can be significantly promoted by active transition metals, such as copper. This type of mixed metal oxide catalyst has stable activity and is resistant to water and carbon dioxide poisoning. The performance of the catalyst was consistently good over a range of $\mathrm{SO}_{2}$ inlet concentration $(0.1$ to $10 \%$ ) indicating its flexibility in treating $\mathrm{SO}_{2}$ tail gases as well as high concentration streams.

The overall objective of the current two-phase program is build on the results described above to advance the $\mathrm{SO}_{2}$-reduction technology from the laboratory to commercial scale. The principal objective of our Phase I program is to identify and evaluate the performance of a catalyst which is robust and flexible with regard to choice of reducing gas (methane, carbon monoxide, or syngas).

\section{Tufts}

Work to date at Tufts University has focused on screening tests of a variety of catalyst formulations. The catalyst preparation technique used consists of mixing a solution of nitrate salts and urea and heating the solution to $100^{\circ} \mathrm{C}$ under strong stirring. Co-precipitation occurs as the solution is heated for $8 \mathrm{hr}$. The precipitate is then filtered, washed twice with hot deionized water, dried overnight, and then calcined in air at $650^{\circ} \mathrm{C}$ for $3 \mathrm{hr}$.

Previously reported results have indicated that:

$\mathrm{Ni}-\mathrm{Ce}(\mathrm{La})-\mathrm{O}$ catalysts show the highest activity, even at relatively low Ni concentrations (2\%).

$\mathrm{La}_{2} \mathrm{O}_{3}$ dopant plays a more important role in the reduction of $\mathrm{SO}_{2}$ by $\mathrm{CH}_{4}$ than in the reduction of $\mathrm{SO}_{2}$ by $\mathrm{CO}$.

Low metal contents are necessary to avoid agglomeration and sintering of the metal oxides at high temperatures.

Use of synthesis gas as the reducing agent can shift the catalyst light-off temperatures back to the values previously reported for pure $\mathrm{CO}$.

The catalysts were prepared by urea gelation/coprecipitation. This method provides well dispersed and homogeneous mixed oxides or mixed oxide compounds, and was used in previous work and for some of the catalysts examined during this reporting period. This preparation consists of the following steps: (i) Mixing nitrate salts of metals with urea and heating the solution to $100^{\circ} \mathrm{C}$ under continuously stirring, (ii) After coprecipitation, boiling the resulting gels of Ce or Zr vigorously for 8 hours; (iii) Filtering and washing the precipitate twice with hot deionized water; (iv) Drying the precipitate overnight in a vacuum oven at $80-100{ }^{\circ} \mathrm{C}$; (v) Crushing the dried lumps into smaller particles and calcining in air for a few hours at $650{ }^{\circ} \mathrm{C}$ for $\mathrm{CeO}_{2}$-based catalysts and $500^{\circ} \mathrm{C}$ for $\mathrm{ZrO}_{2}$-based catalysts. The typical surface area of the thus prepared $\mathrm{CeO}_{2}$-based catalyst was about $70-120 \mathrm{~m}^{2} / \mathrm{g}$. However, the surface area of $\mathrm{CeO}_{2}$ and La$\mathrm{Ce}-\mathrm{O}$ catalysts was not stable even after $750{ }^{\circ} \mathrm{C}$ calcination, and the typical surface area after reaction up to $750{ }^{\circ} \mathrm{C}$ was around $35 \mathrm{~m}^{2} / \mathrm{g}$ (Table 1 ). 
Table 4-1. Physical Properties and Activity of Ceria and Doped Ceria

\begin{tabular}{lccllll}
\hline Sample & \multicolumn{2}{c}{$\begin{array}{c}\text { Surf. area of fresh sample } \\
\left(\mathrm{m}^{2} / \mathrm{g}\right)\end{array}$} & \multicolumn{2}{c}{$\begin{array}{c}\text { Surf. area of used sample* } \\
\text { after reaction at } 750{ }^{\circ} \mathrm{C}\end{array}$} & \multicolumn{2}{c}{$\begin{array}{c}\text { Activity of Sample } \\
\left(\mathrm{T}=700{ }^{\circ} \mathrm{C}\right)\end{array}$} \\
\hline & $\begin{array}{c}650{ }^{\circ} \mathrm{C} \\
\text { calcination }\end{array}$ & $\begin{array}{c}750^{\circ} \mathrm{C} \\
\text { calcination }\end{array}$ & dry & wet & $\mathrm{X}^{-\mathrm{SO}_{2}}$ & $\mathrm{Y}-[\mathrm{S}]$ \\
$\mathrm{CeO}_{2}$ & 75 & 40 & $29(20)$ & 33 & 0.255 & 0.255 \\
$4.5 \% \mathrm{La}-\mathrm{Ce}-$ & 70 & 59 & 33 & & 0.221 & 0.211 \\
$\mathrm{O}$ & & & & & & \\
$10 \% \mathrm{La}-\mathrm{Ce}-\mathrm{O}$ & 106 & 69 & 37 & & 0.236 & 0.226 \\
$20 \% \mathrm{La}-\mathrm{Ce}-\mathrm{O}$ & 120 & 58 & $34(30)$ & 28 & 0.299 & 0.291 \\
$30 \% \mathrm{La}-\mathrm{Ce}-\mathrm{O}$ & 78 & 59 & 35 & & 0.206 & 0.198 \\
\hline
\end{tabular}

*all catalysts were pre-reduced (at $600{ }^{\circ} \mathrm{C}$ in $10 \% \mathrm{CO} / \mathrm{He}$ for $1 \mathrm{hr}$ ).

The values in parenthesis are the surface area of the samples calcined at $750{ }^{\circ} \mathrm{C}$.

All catalysts were tested in a laboratory-scale, quartz tube packed bed flow reactor with a porous quartz frit supporting the catalyst, which was in powder form. A 0.5 in. O.D. x 18.5 in. long bed was used in catalyst tests. The experiments were carried out under nearly atmospheric pressure. A cold trap connected at the outlet of the reactor was used to separate and collect the elemental sulfur and water from the product stream. The product gas was analyzed by a HP5880A Gas Chromatograph (GC) with a Thermal Conductivity Detector(TCD). A 1/4 in. O.D. x 6 in. long packed glass column of Chromosil 310 was used in the $\mathrm{GC}$ to detect $\mathrm{CO}, \mathrm{CO}_{2}, \mathrm{COS}, \mathrm{SO}_{2}, \mathrm{CS}_{2}$ and $\mathrm{H}_{2} \mathrm{~S}$.

The results are shown in terms of sulfur dioxide conversion, $\mathrm{X}-\mathrm{SO}_{2}$, and elemental sulfur yield, Y-[S], defined as follows:

$$
\begin{gathered}
X\left(\mathrm{SO}_{2}\right)=\frac{\left(\left[\mathrm{SO}_{2}\right]_{0}-\left[\mathrm{SO}_{2}\right]\right)}{\left[\mathrm{SO}_{2}\right]_{0}} \\
Y(\mathrm{~S})=\frac{[\mathrm{S}]}{\left[\mathrm{SO}_{2}\right]_{0}}
\end{gathered}
$$

where $\left[\mathrm{SO}_{2}\right]_{0}$ and $\left[\mathrm{SO}_{2}\right]$ are the inlet and outlet sulfur dioxide concentrations, respectively, while $[\mathrm{S}]$ is the outlet elemental sulfur concentration. [S] is calculated from the difference:

$$
[\mathrm{S}]=\left[\mathrm{SO}_{2}\right]_{0}-\left[\mathrm{H}_{2} \mathrm{~S}\right]-[\mathrm{COS}]-\left[\mathrm{SO}_{2}\right]
$$

The effect of water at high concentrations, such as might be observed during transients in the operation of a large scale unit, were investigated using the standard protocol described above. The catalysts consisted of both $\mathrm{CeO}_{2}$ and La-promoted $\mathrm{CeO}_{2}$, containing 5 or $10 \% \mathrm{Ni}$. The concentration of water was set at either $10 \mathrm{vol} \%$ or $40 \mathrm{vol} \%$ of the feed, using a pump and hot block. The reducing agent was $\mathrm{CO}$ in all of these studies since, by itself, it produces no $\mathrm{H}_{2} \mathrm{~S}$ (and only trace quanties of COS under these conditions). For the rare earths alone, adding water strongly decreased the overall conversion at temperatures below about $500^{\circ} \mathrm{C}$ (Figure 4-1a). At higher temperatures, some of the activity was regained but the selectivity changed to produce significant quantities of $\mathrm{H}_{2} \mathrm{~S}$ (Figure 4-1b). 

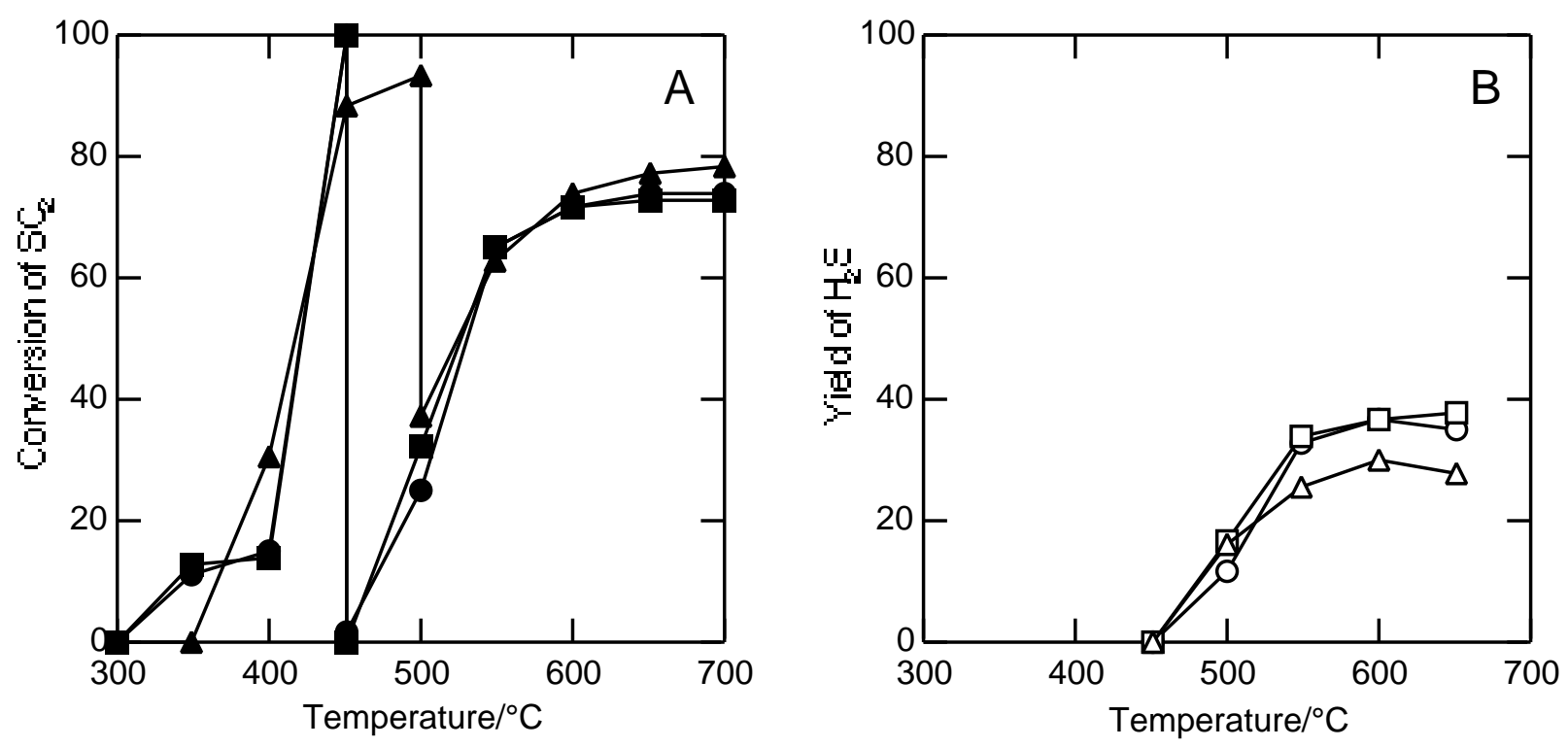

Figure 4-1. Reduction of $1.05 \% \mathrm{SO}_{2}$ by $\mathrm{CO}$ over ceria and promoted ceria with and without adding $10 \%$ water (at either $450^{\circ} \mathrm{C}$ or $500^{\circ} \mathrm{C}$ as indicated by the arrows). Contact time $=0.11 \mathrm{~g}$ $\mathrm{s} / \mathrm{cm}^{3}, \mathrm{CO} / \mathrm{SO}_{2}=1.5$ to 1.6. Catalysts:,$-\mathrm{Ce}(10 \% \mathrm{Zr}) \mathrm{O}_{2} ; \mathbf{\square},-\mathrm{Ce}\left(10 \% \mathrm{La}^{-} \mathrm{O}_{2} ; \boldsymbol{\Delta}, \triangle-\right.$ $\mathrm{CeO}_{2}$. Filled symbols represent conversion of $\mathrm{SO}_{2}$; open symbols represent yield to $\mathrm{H}_{2} \mathrm{~S}$..

The effect of adding water is reversible, over at least 8 hours of continuous addition (Figure 4-2).

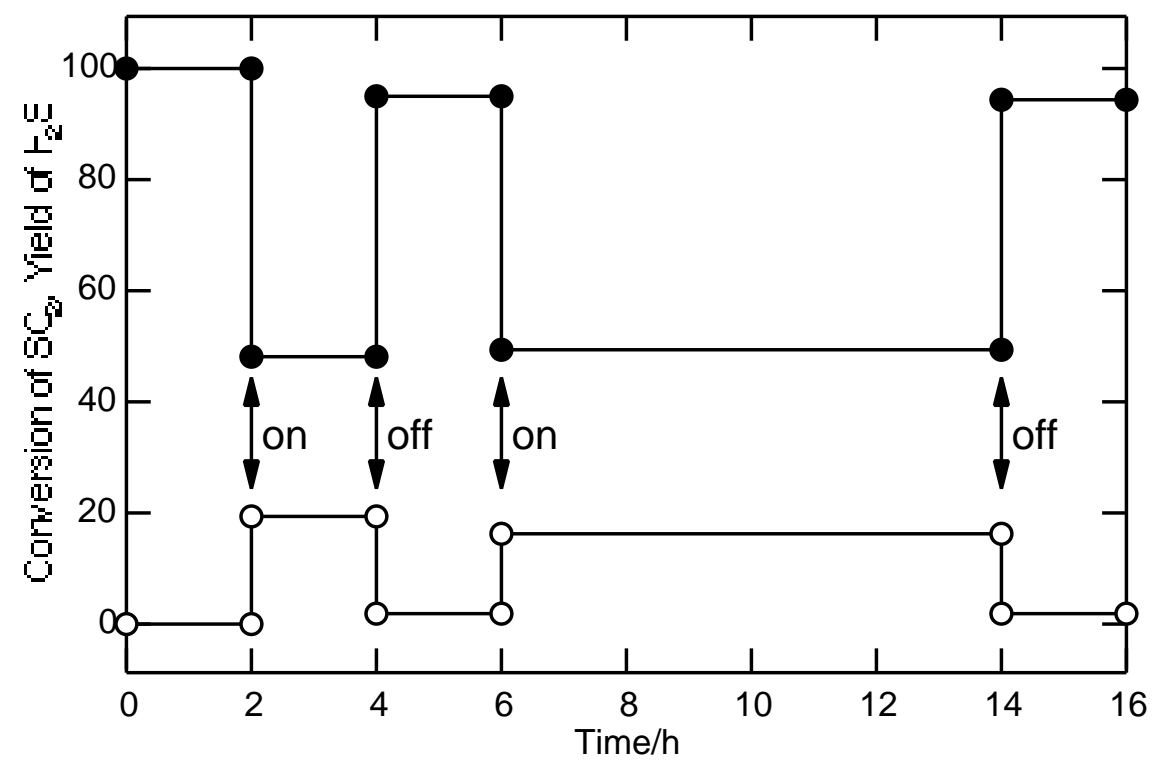

Figure 4-2. Reduction of $1.1 \% \mathrm{SO}_{2}$ by $\mathrm{CO}$ over $\mathrm{Ce}(10 \% \mathrm{Zr}) \mathrm{O}_{2}$ at $500^{\circ} \mathrm{C}$. Conditions: contact time $=0.11 \mathrm{~g} \mathrm{~s} / \mathrm{cm}^{3}, \mathrm{CO} / \mathrm{SO}_{2}=1.51$. At the indicated times, $10 \%$ water was added or removed from the inlet stream. Filled symbols represent conversion of $\mathrm{SO}_{2}$; open symbols represent yield to $\mathrm{H}_{2} \mathrm{~S}$.

The Ni-containing catalysts maintained a significant level of activity in the presence of water (Figures 4-3a,b) but still produced substantial quantities of $\mathrm{H}_{2} \mathrm{~S}$, albeit at longer contact times. It should be noted, however, that the results shown in Figure 4-3 represent very severe conditions 
with respect to water. Additional tests to more closely match the existing conditions of the major types of adsorbent-regenerators (i.e. <10\% water) are underway.
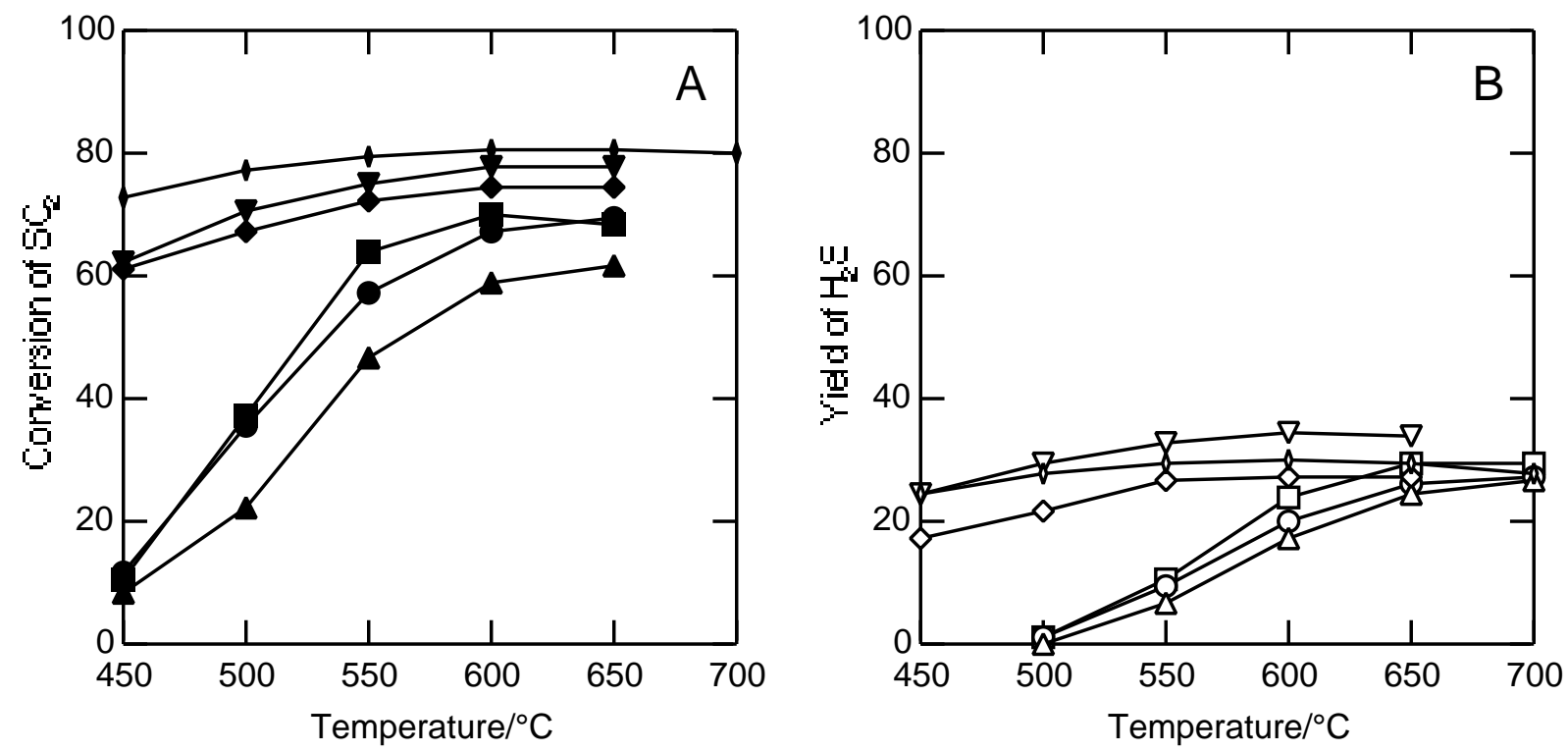

Figure 4-3. Reduction of $1.05 \% \mathrm{SO}_{2}$ by $\mathrm{CO}$ in the presence of $10 \%$ water. Conditions: contact time $=0.11 \mathrm{~g} \mathrm{~s} / \mathrm{cm}^{3}$ (except as indicated), $\mathrm{CO} / \mathrm{SO}_{2}=1.5-1.7$. Catalysts: $\mathbf{O}-\mathrm{Ce}(10 \% \mathrm{Zr}) \mathrm{O}_{2} ; \mathbf{\square}$,

$-\mathrm{Ce}(10 \% \mathrm{La}) \mathrm{O}_{2} ; \boldsymbol{\Delta}, \triangle-\mathrm{CeO}_{2} ; \boldsymbol{\nabla}, \nabla-10 \% \mathrm{Ni}\left[\mathrm{Ce}(5 \% \mathrm{La}) \mathrm{O}_{\mathrm{x}}\right] ; \diamond,-10 \% \mathrm{Ni}\left[\mathrm{Ce}\left(5 \% \mathrm{La}^{-} \mathrm{O}_{\mathrm{x}}\right]\right.$ pre-reduced at $600^{\circ} \mathrm{C}$ in flowing hydrogen; $\mathbf{L},-\mathrm{Ni}_{\mathrm{y}}\left[\mathrm{Ce}\left(\mathrm{La}_{1-\mathrm{y}}\right) \mathrm{O}_{\mathrm{x}}\right]$. Filled symbols represent conversion of $\mathrm{SO}_{2}$; open symbols represent yield to $\mathrm{H}_{2} \mathrm{~S}$..

While the addition of $\mathrm{Ni}$ and $\mathrm{Cu}$ improved the activity of $\mathrm{Ce}(\mathrm{La}) \mathrm{O}_{\mathrm{x}}$ for $\mathrm{SO}_{2}$ reduction by $\mathrm{CO}$ both in dry and wet gas stream, the addition of $\mathrm{Ni}$ and $\mathrm{Cu}$ had negligible effect on the activity of $\mathrm{Ce}(\mathrm{La}) \mathrm{O}_{\mathrm{x}}$ catalyst for $\mathrm{SO}_{2}$ reduction by $\mathrm{CH}_{4}$. Figure 4-4 shows that at a contact time of $0.18 \mathrm{~g}$ s/cc and $\mathrm{SO}_{2} / \mathrm{CH}_{4}=1,4.5 \% \mathrm{La}-\mathrm{Ce}-\mathrm{O}$ had higher $\mathrm{SO}_{2}$ conversion than $\mathrm{Ni}$ and $\mathrm{Cu}$ modified $\mathrm{Ce}(\mathrm{La}) \mathrm{O}_{\mathrm{X}}$, while the latter two catalysts showed slightly higher selectivity to sulfur. The same result was obtained at higher contact times of $0.36 \mathrm{gs} / \mathrm{cc}$ and $0.72 \mathrm{gs} / \mathrm{cc}$. The lack of activity enhancement by the metal modified catalysts may be explained by the fact that the metals only promote the reducibility of ceria at low temperature, whereas high temperature are needed for the methane activation. 

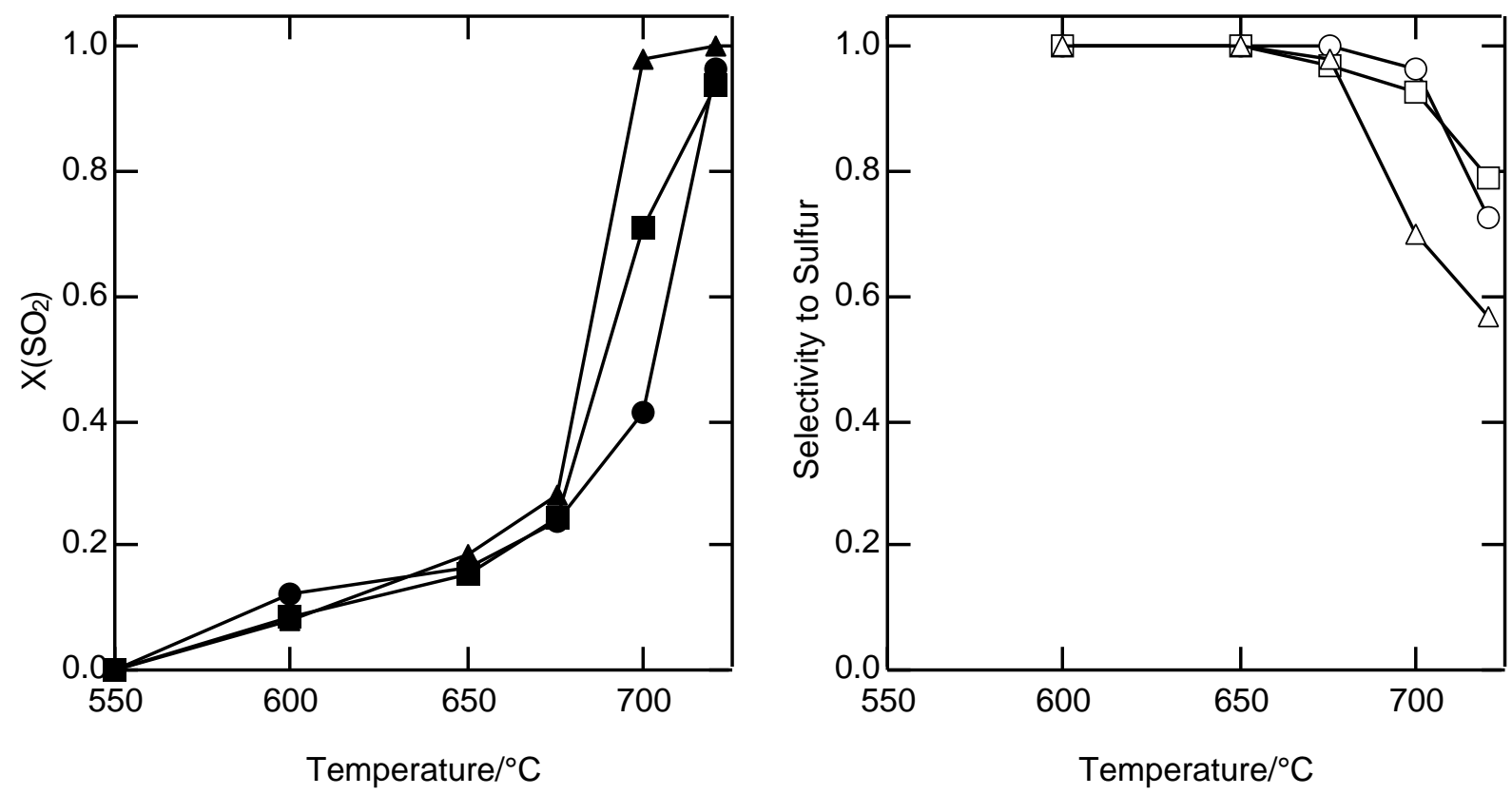

Figure 4-4. Effect of catalysts composition on $\mathrm{SO} 2$ reduction by $\mathrm{CH} 4$. Catalysts: $-5 \% \mathrm{Ni}-$ $\mathrm{Ce}(\mathrm{La})-\mathrm{O} ; \mathbf{\square},: 5 \% \mathrm{Cu}-\mathrm{Ce}(\mathrm{La})-\mathrm{O} ; \mathbf{\Delta}, \triangle: 4.5 \% \mathrm{La}-\mathrm{Ce}-\mathrm{O}$. Conditions: $1 \% \mathrm{SO}_{2}-1 \% \mathrm{CH}_{4}$-balance $\mathrm{He}$, contact time $0.18 \mathrm{gs} / \mathrm{cm}^{3}$.

We then focused our parametric studies on the $5 \% \mathrm{Cu}-\mathrm{Ce}(\mathrm{La})-\mathrm{O}$ catalysts, which showed slightly higher selectivity(Figure 1). Figure 4-5 shows the effect of contact time on $5 \% \mathrm{Cu}-\mathrm{Ce}(\mathrm{La})-\mathrm{O}$ catalysts. The activity of the catalyst was increased by increasing the contact time, and the selectivity to sulfur (defined as the ratio of $\mathrm{Y}-[\mathrm{S}] / \mathrm{X}-\mathrm{SO}_{2}$ ) was decreased when the contact time increased from 0.18 to $1.2 \mathrm{gs} / \mathrm{cm}^{3}$. This was consistent with the previous result of $\mathrm{Ni}-\mathrm{Ce}(\mathrm{La})-\mathrm{O}$ catalyst, implying that elemental sulfur is the primary product in the $\mathrm{SO}_{2}$ reduction by $\mathrm{CH}_{4}$, while $\mathrm{H}_{2} \mathrm{~S}$ and $\mathrm{COS}$, if formed, are secondary products.
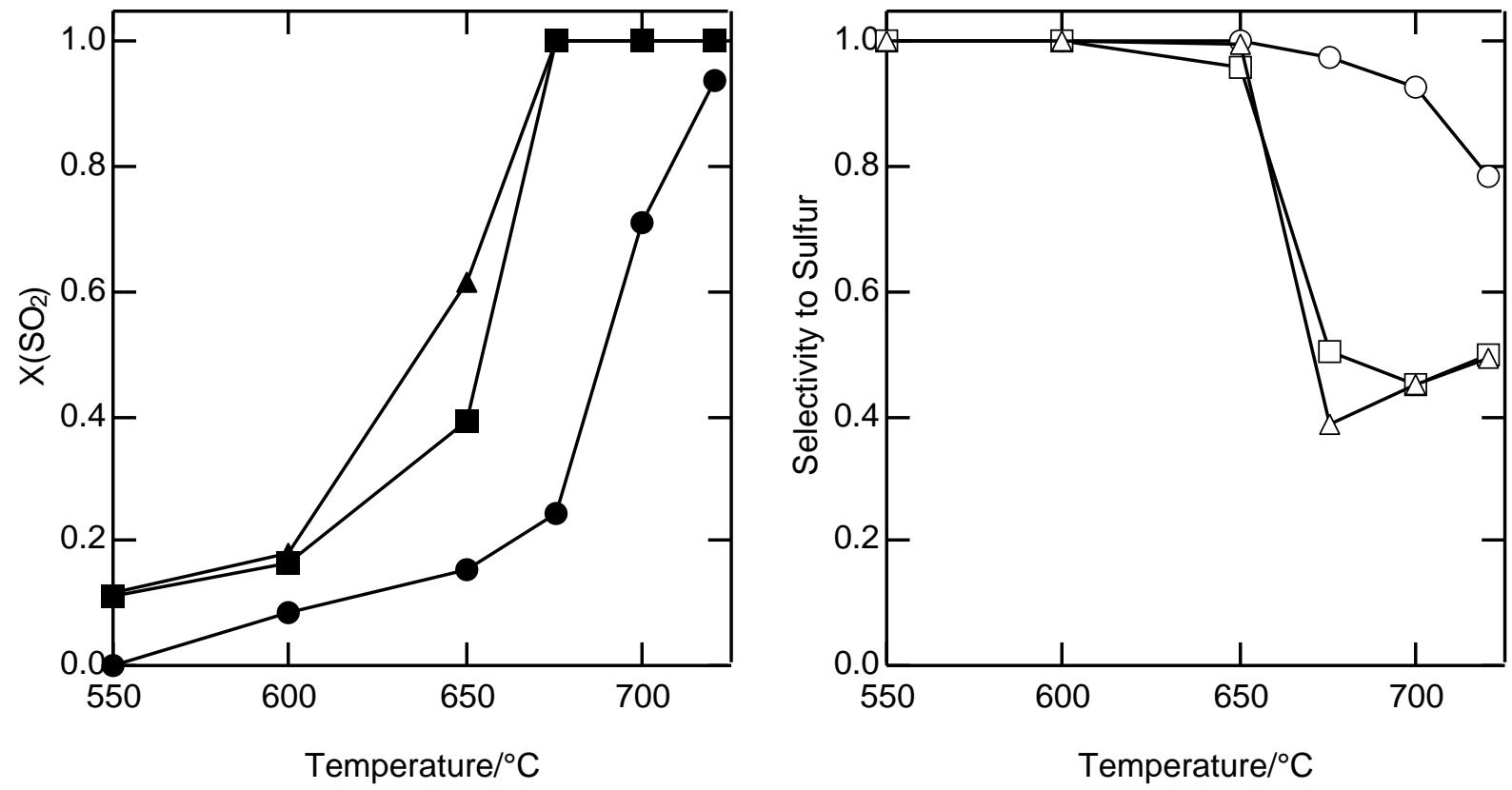
Figure 4-5. Effect of contact time on $\mathrm{SO}_{2}$ reduction by $\mathrm{CH}_{4}$. Catalyst: $5 \% \mathrm{Cu}-\mathrm{Ce}(\mathrm{La})-\mathrm{O}$.

Conditions: $1 \% \mathrm{SO}_{2}-1 \% \mathrm{CH}_{4}$-balance $\mathrm{He}$, contact time $, 0.18 \mathrm{gs} / \mathrm{cc}, \mathbf{\square}, \quad: 0.72 \mathrm{gs} / \mathrm{cc}$ and $\boldsymbol{\Delta}$, $: 1.2 \mathrm{gs} / \mathrm{cm}^{3}$.

The higher the ratio of $\mathrm{CH}_{4}$ to $\mathrm{SO}_{2}$, the higher the activity and the lower the selectivity of the catalysts, as shown in Figure 4-6. Interestingly, the results indicated that the reaction had a positive dependence on methane, therefore by using excess methane we could lower the reaction temperature, keeping both high activity and selectivity. This is a very important finding for developing a process with maximum activity and selectivity.
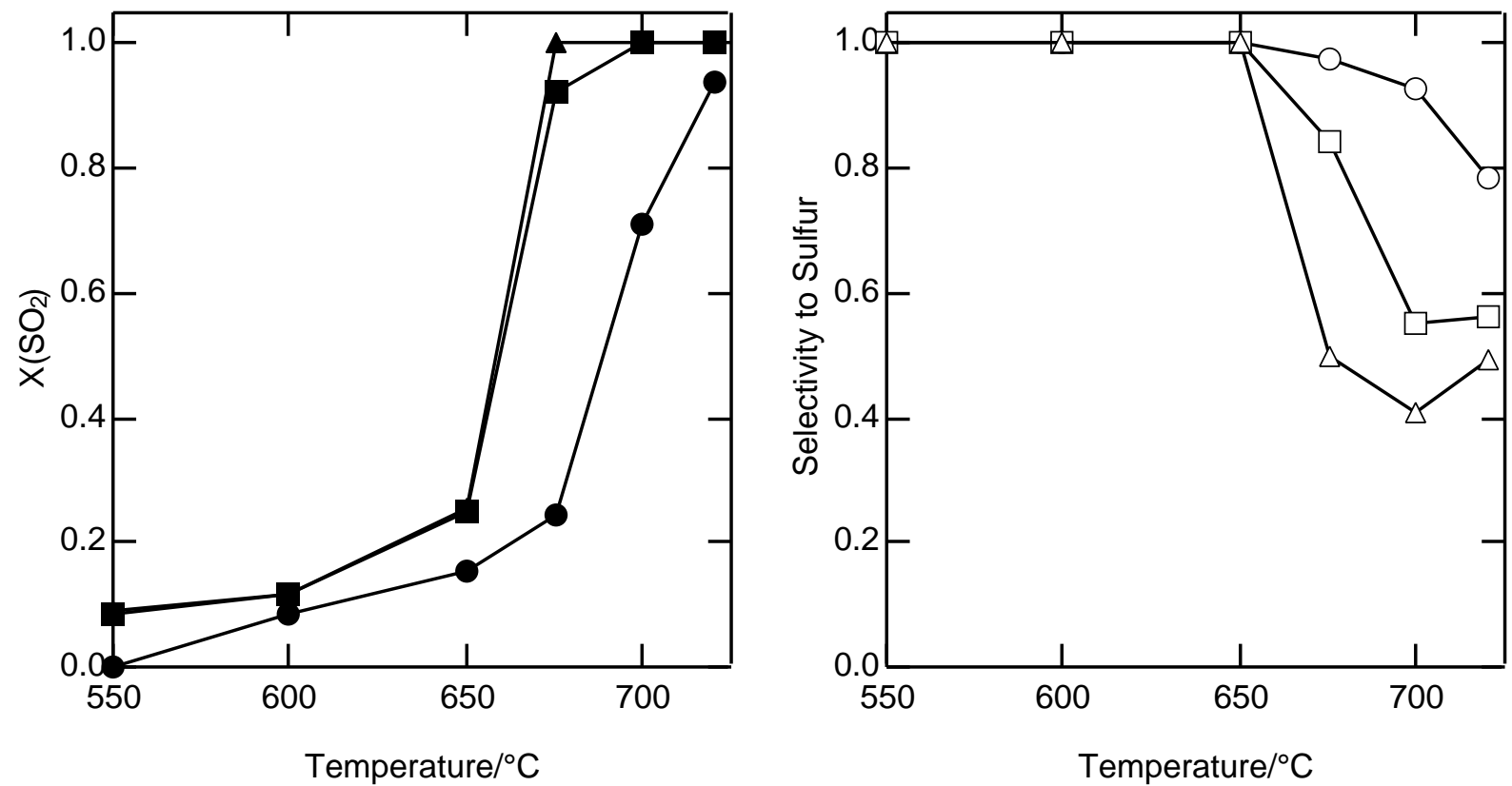

Figure 4-6. Effect of $\mathrm{CH}_{4} / \mathrm{SO}_{2}$ ratio on $\mathrm{SO}_{2}$ reduction by $\mathrm{CH} 4$. Catalyst: $5 \% \mathrm{Cu}-\mathrm{Ce}(\mathrm{La})-\mathrm{O}$. Conditions: $1 \% \mathrm{SO}_{2}$, contact time $0.18 \mathrm{gs} / \mathrm{cm}^{3}, \mathrm{CH}_{4} / \mathrm{SO}_{2}: \mathbf{O},-1 ; \mathbf{\square},-2 ; \boldsymbol{\Delta}, \triangle-3$. .

The activity was decreased when $5 \% \mathrm{H}_{2} \mathrm{O}$ was added into the feed stream as indicated in Figure 4-7. However, the selectivity was still high and almost all the $\mathrm{SO}_{2}$ was converted to sulfur. The activity of the catalyst could be recovered when water was removed from the feed stream and no aging effect was observed during a 20-hr long test. 


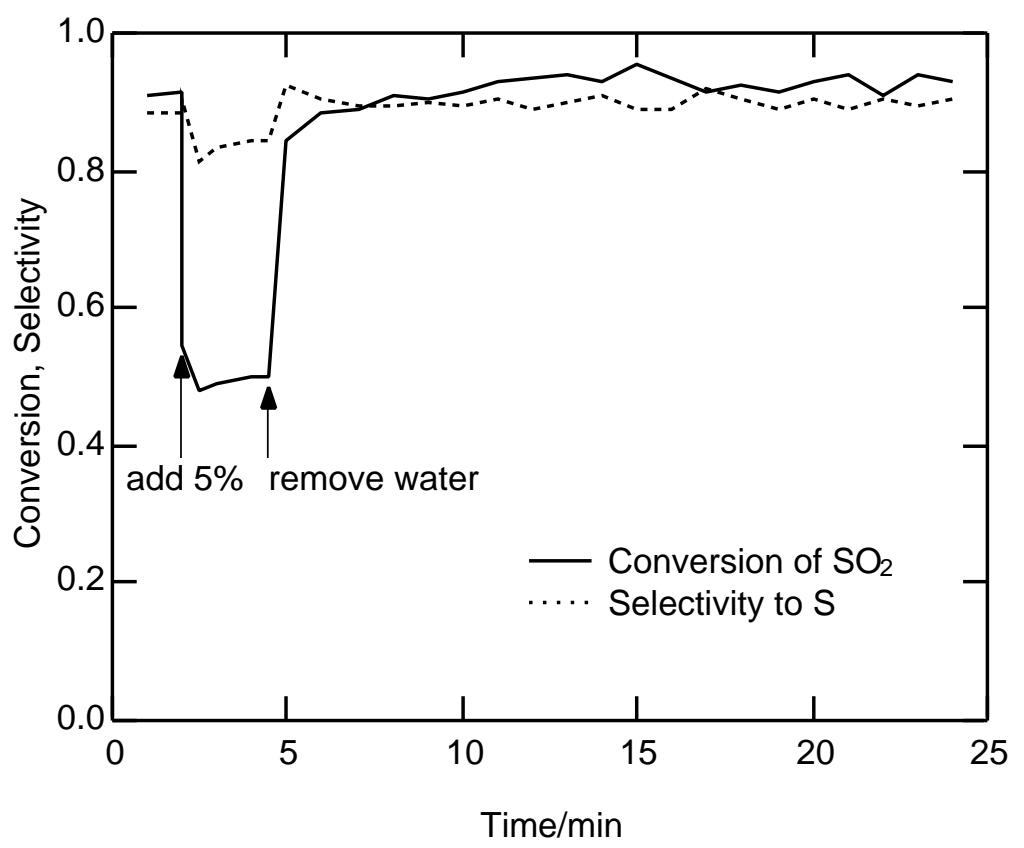

Figure 4-7. Effect of water on $\mathrm{SO}_{2}$ reduction by $\mathrm{CH}_{4}$. Conditions: $1 \% \mathrm{SO}_{2}-2 \% \mathrm{CH}_{4}-\mathrm{He}$, contact time $0.18 \mathrm{gs} / \mathrm{cm}^{3}$.

One of the possible paths for $\mathrm{H}_{2} \mathrm{~S}$ formation during $\mathrm{SO}_{2}$ reduction by $\mathrm{CH}_{4}$, is via the $\mathrm{H}_{2}$ produced by methane pyrolysis:

$$
\mathrm{CH}_{4} \rightarrow 2 \mathrm{H}_{2}+\mathrm{C}
$$

Hydrogen may then attack the adsorbed sulfur to form $\mathrm{H}_{2} \mathrm{~S}$. As described above, by operating at low temperature, we can prevent methane pyrolysis (i.e. $\mathrm{H}_{2}$ formation ) and maximize sulfur yield. Hydrogen as a reductant is also of interest for the direct reduction of $\mathrm{SO}_{2}$ to elemental sulfur. Therefore, the reduction of $\mathrm{SO}_{2}$ by $\mathrm{H}_{2}$ was studied on $\mathrm{Ce}(\mathrm{La}) \mathrm{O}_{\mathrm{x}}$ and metal modified ceria catalysts. $\mathrm{Ce}(\mathrm{La}) \mathrm{O}_{\mathrm{x}}$ was found to be an active catalyst and the light-off behavior was similar to that for $\mathrm{SO}_{2}$ reduction by $\mathrm{CO}$, as shown in Figure 4-8. The performance of this catalyst could be explained by the redox model in which $\mathrm{CO}$ is simply replaced by $\mathrm{H}_{2}$ as the reductant. However, the light-off temperature was inferior to $\mathrm{CO}$, in that a higher temperature was required. 

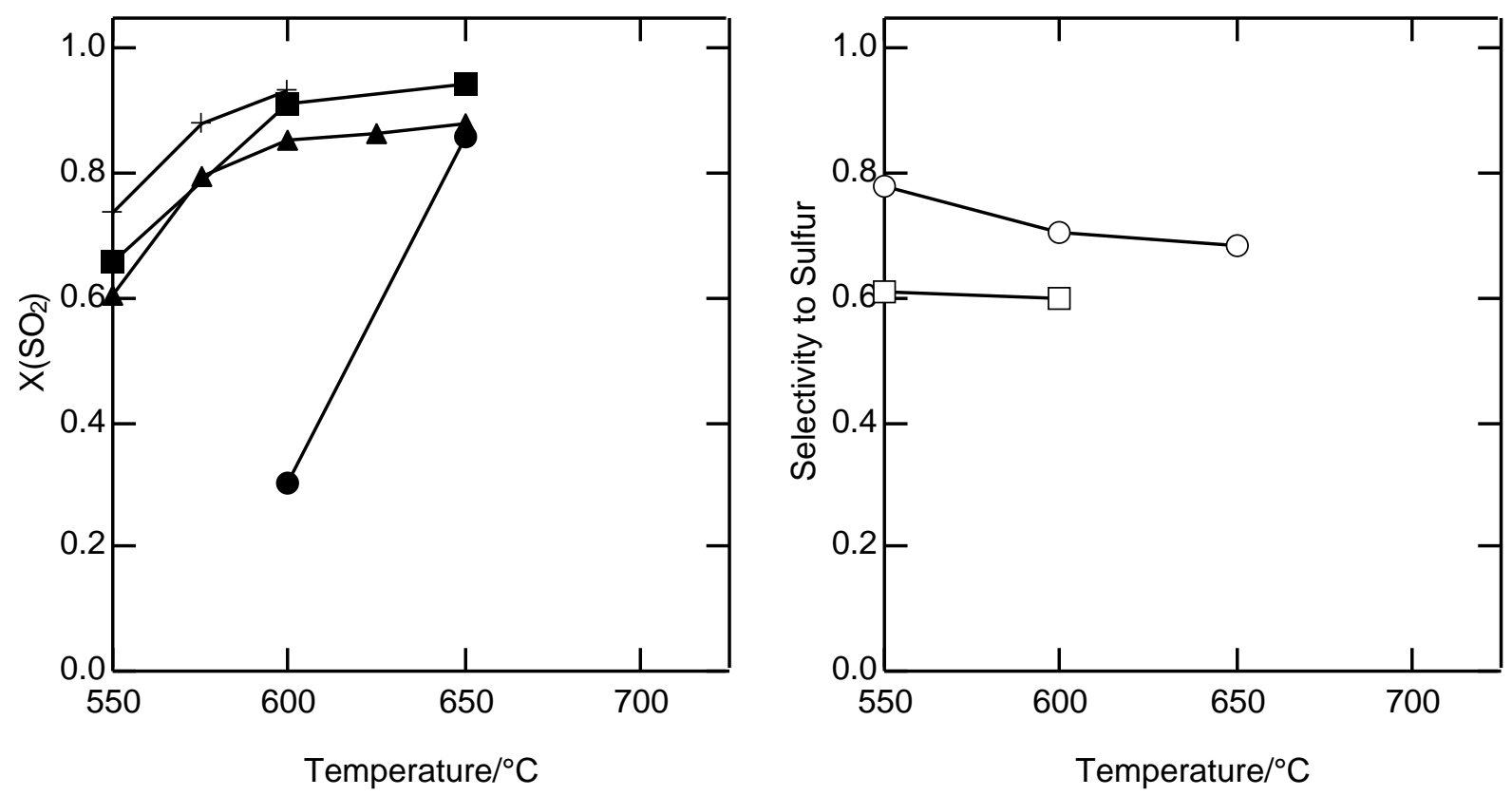

Figure 4-8. Effect of metal on the reduction of $\mathrm{SO}_{2}$ by $\mathrm{H}_{2}$ : activity of $\mathrm{Ce}(\mathrm{La}) \mathrm{O}_{x}$. Catalysts: $4.5 \% \mathrm{La}-\mathrm{Ce}-\mathrm{O} ; \boldsymbol{\square}, \quad: 5 \% \mathrm{Fe}-\mathrm{Ce}(\mathrm{La})-\mathrm{O} ; \boldsymbol{\Delta}, \triangle \mathbf{5}^{2} \mathrm{Cu}-\mathrm{Ce}(\mathrm{La})-\mathrm{O} ; \bullet,: 5 \% \mathrm{Ni}-\mathrm{Ce}(\mathrm{La})-$ O.Conditions: $1 \% \mathrm{SO}_{2}-2 \% \mathrm{H}_{2}-\mathrm{He}$, contact time $0.18 \mathrm{gs} / \mathrm{cm}^{3}$.

By adding $5 \% \mathrm{Cu}, \mathrm{Ni}$ or $\mathrm{Fe}$ into $\mathrm{Ce}(\mathrm{La}) \mathrm{O}_{x}$ catalyst, the light-off temperature was decreased by about $100{ }^{\circ} \mathrm{C}$ (Figure 4-8). However, the presence of $\mathrm{H}_{2}$ promotes the production of $\mathrm{H}_{2} \mathrm{~S}$, and the highest sulfur yield obtained was $64 \%$ when feed gas stream contained $1 \% \mathrm{SO}_{2}$ and $2 \% \mathrm{H}_{2}$ at a contact time of $0.18 \mathrm{gs} / \mathrm{cm}^{3}\left(\sim 40,000 \mathrm{~h}^{-1}\right)$.

It is clear from Liu's thesis work[4] on $\mathrm{SO}_{2}$ reduction by $\mathrm{CO}$ that the activity of $\mathrm{Cu}-\mathrm{Ce}(\mathrm{La})-\mathrm{O}$ was not sensitive to metal content. The reducibility of catalysts, i.e., the oxygen vacancy and oxygen mobility, which was the key for the reaction of $\mathrm{SO}_{2}$ and $\mathrm{CO}$, was not affected by metal content. However, in the case of the $\mathrm{H}_{2}+\mathrm{SO}_{2}$ reaction, a positive effect of the incorporation of iron was identified. Figure 4-9 shows that the $\mathrm{SO}_{2}$ conversion and sulfur yield of Fe-Ce(La)-O catalysts was enhanced by the addition of more iron. More experiments with high content of metal are necessary to pursue the effect of metal content on the activity and selectivity of the catalysts . 

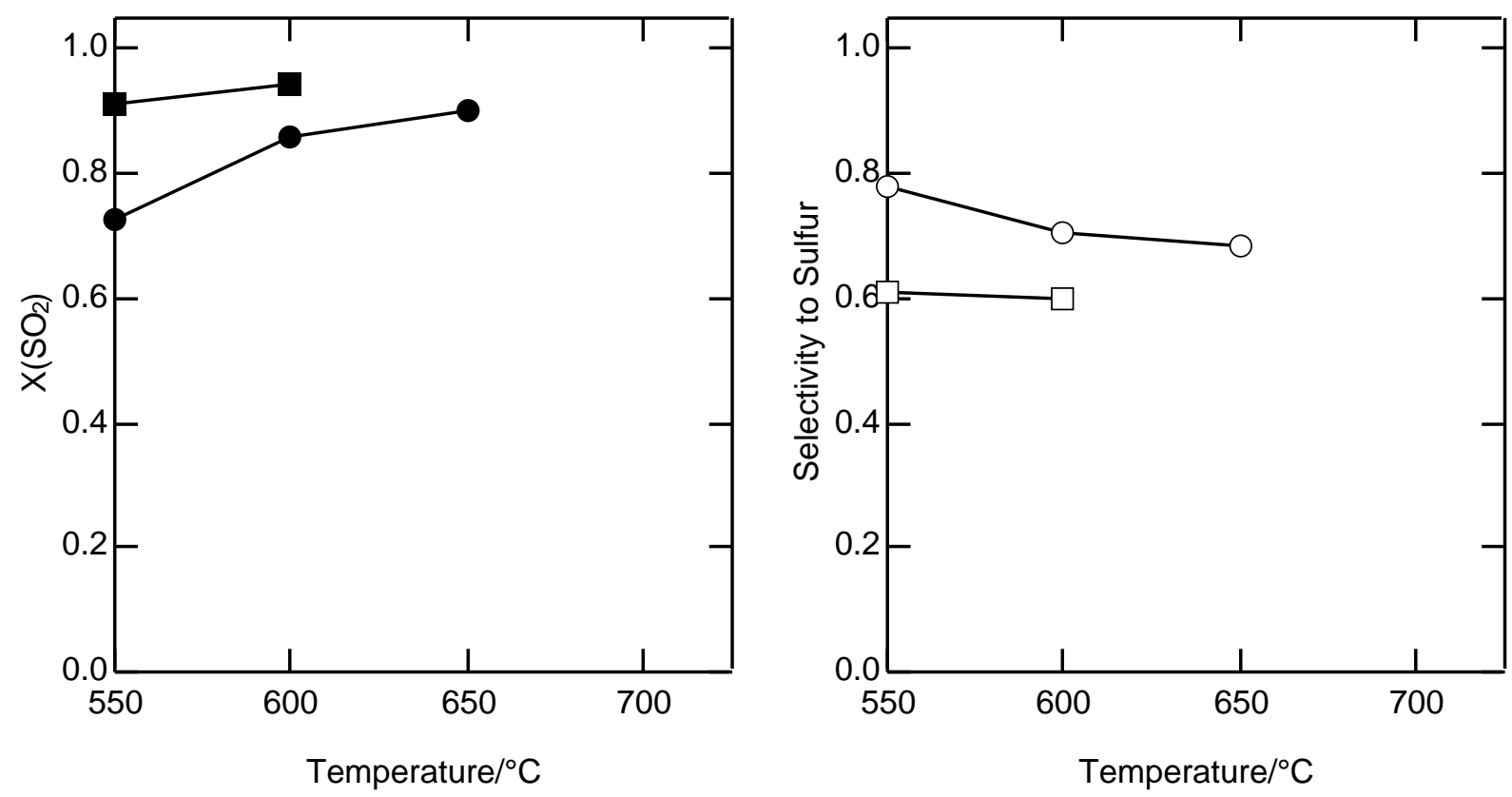

Figure 4-9. Effect of metal content on the reduction of $\mathrm{SO}_{2}$ by $\mathrm{H}_{2}$. Catalysts: $-15 \% \mathrm{Fe}-$ $\mathrm{Ce}(\mathrm{La})-\mathrm{O} ; \mathbf{\square}, \quad: 5 \% \mathrm{Fe}-\mathrm{Ce}(\mathrm{La})-\mathrm{O}$. Conditions: $1 \% \mathrm{SO}_{2}, 2 \% \mathrm{H}_{2}$, balance $\mathrm{He}$, contact time 0.18 $\mathrm{gs} / \mathrm{cm}^{3}$.

\section{Arthur D. Little}

The bench scale reactor has been completed and partly shaken down. Discussions with our colleagues at Tufts have focus the experimental plan to include sets of catalysts and test conditions that likely will meet the design goals of the overall conversion process using $\mathrm{CO}$, synthesis gas or methane as the reducing agent, both with and without water. We are in the process of testing an initial catalyst $\left(1 \% \mathrm{Cu} / \mathrm{CeO}_{2}\right.$ provided to us by Engelhard). The preliminary results suggest that the catalyst is active and that we will be able to operate the reactor so as to scale up the results from Tufts.

Operation of this larger scale reactor has reinforced a practical detail that would attend a commercial scale system. It is apparent that the catalyst must effect the desired conversion in a single pass: separation of the sulfur requires cooling of the effluent stream, which would then need to be reheated if it were to be recycled.

Industry contacts. The following individuals have agreed to serve as an industrial review panel to evaluate the technical feasibility and to critique the practical details of implementing a sulfur conversion process based on this catalytic technology:

Jeri Catherine Penrose of Sargent \& Lundy. She is a senior engineer involved with the DOE piloting operation of the $\mathrm{CuO}$ clean up system.

Randall Rush, of the Southern Company. He is Director of their advanced coal gasification program and is directing thie demonstration facility at Wilsonville 
where they will be hosting an RTI technology test.

William Ellison, an independent FGD consultant. Mr. Ellison has been involved in much of the innovative flue gas desulfurization technology in utility and other industries.

Krishna Parmeswaran, of ASARCO. He has more than 20 years of experience in the smelting business.

We are still in the process of identifying one or two others who have experience in the design of utility burners and in the petrochemical industry.

\section{Engelhard}

Additional catalyst materials were supplied to Tufts for testing prior to washcoating them onto the monoliths. The $\mathrm{Cu}$-based catalyst performed well and was incorporated into a monolith that was shipped to ADL.

\section{References:}

(1) National Coal Association "Steam Electric Plant Factors,", 1992.

(2) Henzel, D. S.; Ellision, W. Proceedings: $1990 \mathrm{SO}_{2}$ Control Symposium 1990, Volume 1, 3B-27.

(3) Tyson, S. Proceedings of the 9th Annual International Pittsburgh Coal Conference 1992.

(4) Liu, W.; Sarofim, A. F.; Flytzani-Stephanopoulos, M. Applied Catalysis B: Environmental 1994, 4, 167-186.

(5) Trovarelli, A. Catal. Rev., Sci. Eng. 1996, 138, 439-520. 